\title{
FAKTOR-FAKTOR YANG BERHUBUNGAN DENGAN KEJADIAN PNEUMONIA PADA BALITA DI UPTD PUSKESMAS KEMALARAJA KABUPATEN OKU TAHUN 2019
}

\author{
Yustina Oktarida, SKM.,M.Kes \\ DOSEN DIPLOMA III KEBIDANAN \\ STIKES AL-MA'ARIF BATURAJA \\ E-mail: yustinaoktarida647@gmail.com
}

\begin{abstract}
ABSTRAK
Latar Belakang: Pneumonia merupakan salah satu penyakit infeksi saluran pernafasan akut bagian bawah yang menjadi penyebab utama morbiditas dan mortalitas anak berusia dibawah lima tahun terutama di negara yang sedang berkembang. Kematian balita di Indonesia yang disebabkan penyakit respiratori terutama adalah pneumonia (Said, 2012). Tujuan: Untuk mengetahui Faktor-faktor yang berhubungan dengan kejadian pneumonia pada balita di UPTD Puskesmas Kemalaraja Kabupaten OKU Tahun 2019. Metode: Penelitian ini menggunakan metode analitik dengan pendekatan cross sectional. Populasi dalam penelitian adalah ibu yang memiliki balita di UPTD Puskesmas Kemalaraja Kabupaten Ogan Komering Ulu pada bulan Juli Tahun 2019 yang berjumlah 65 orang. Analisa data menggunakan analisa univariat dan analisa bivariat dengan menggunakan tabel distribusi dan uji statistik Chi-Square, dengan derajat kepercayaan $95 \%$. Hasil penelitian: Pada analisa bivariat didapatkan ada hubungan yang bermakna antara Status Imunisasi dengan Kejadian Pneumonia dengan $p$ value 0,005, ada hubungan yang bermakna antara Pemberian ASI Eksklusif dengan Kejadian Pneumonia dengan $p$ value 0,021 , dan ada hubungan yang bermakna antara berat badan lahir dengan Kejadian Pneumonia dengan $p$ value 0,002 . Kesimpulan: Ada hubungan yang bermakna antara Status Imunisasi , pemberian ASI Ekslusif, berat badan lahir dengan Kejadian Pneumonia
\end{abstract} Kata Kunci : ASI Eksklusif, Berat Badan Lahir, Kejadian Pneumonia, Status Imunisasi

\section{ABSTRACK}

Background: Pneumonia is a disease of acute lower respiratory tract infection which is a major cause of morbidity and mortality in children under five years old especially in developing countries. Infant mortality in Indonesia caused by respiratory disease is primarily pneumonia (Said, 2012). Objective: To determine the factors associated with the incidence of pneumonia in infants in UPTD Puskesmas Kemalaraja OKU Regency in 2019. Method: This research uses analytic method with cross sectional approach. The population in this study was mothers who had children under five years old at UPTD Puskesmas Kemalaraja, Ogan Komering Ulu Regency in July 2019, amounting to 65 people. Data analysis uses univariate analysis and bivariate analysis using distribution tables and Chi-Square statistical tests, with a 95\% confidence level. Results: In the bivariate analysis there was a significant relationship between immunization status with the incidence of pneumonia with $p$ value 0.005 , there was a significant relationship between exclusive breastfeeding with the incidence of pneumonia with $p$ value 0.021 , and there was a significant relationship between birth weight and the incidence of pneumonia with $p$ value 0.002 . Conclusion: There is a significant relationship between immunization status, exclusive breastfeeding, birth weight and the incidence of pneumonia.

Keywords: Exclusive ASI, Birth Weight, Pneumonia Occurrence, Immunization Status 


\section{PENDAHULUAN}

Pembangunan Milenium MDGs (Millenium development Goals) pada tahun 2015 yaitu untuk meningkatkan kualitas penduduk dunia dengan delapan sasaran MDGs. Dimana sasaran keempat dan kelima terkait langsung dengan kesehatan ibu, bayi baru lahir, dan balita. Salah satu target MDGs 5 adalah menurunkan AKI atau maternal mortality ration (MMR) hingga tiga perempatnya dari tahun 1991. Berdasarkan Surve Demografi dan Kesehatan Indonesia (SDKI) tahun 1991. AKI adalah 390 kematian per 100.000 kelahiran hidup. Dengan demikian, target AKI di Indonesia pada tahun 2015 adalah 102 kematian per 100.000 kelahiran hidup. Namun, hasil SDKI tahun 2007 menunjukan bahwa AKI baru dapat diturunkan menjadi 228 kematian per 100.000 kelahiran hidup (SDKI, 2012)

Penyebab kematian ibu yang terbesar adalah pendarahan pada masa kehamilan, persalinan, dan postpartum. Pendarahan tersebut dapat terjadi pada ibu yang mengalami anemia. Kematian ibu yang disebabkan karena pendarahan $(34,3 \%)$, dan kondisi yang memburuk kesehatan ibu karena faktor anemia adalah (2,6\%) (Depkes, 2013)

Anemia pada wanita hamil merupakan masalah kesehatan yang dialami oleh wanita diseluruh dunia, terutama di negara berkembang. Anemia adalah suatu keadaan adanya penurunan kadar hemoglobin, hematokrit, dan atau jumlah eritrosit diabawah nilai normal. Peningkatan volume plasma pada ibu hamil meyebabkan terjadinya hemodelusi, sehingga terjadi penurunan hematokrit (20$30 \%$, yang mengakibatkan kadar hemoglobin dan hematokrit lebih rendah dari pada keadaan tidak hamil ( Depkes, 2013)

Tindakan yang dilakukan untuk mengtatasi masalah tersebut selama ini adalah pendistribusian tablet $\mathrm{Fe}$ melalui posyandu, polindes, puskesmas dan melibatkan petugas puskesmas seperti: bidan, perawat hingga kader posyantu. Faktor utama yang menyebabkan sulitnya prevalensi anemia ini antara lain karena rendahnya cakupan distribusi dan kepatuhan ibu mengkonsumsi tablet besi (Depkes, 2013).

Anemia yang disebabkan definisi tablet Fe merupakan tablet resiko kelahiran preterm menyebabkan BBRL dan kesehatan neonatal rebdah dan terbelakang. Pemberian tablet $\mathrm{Fe}$ dapat memperbaiki status Tablet $\mathrm{Fe}$ ibu selama hamil dan postpartum, sehingga tablet $\mathrm{Fe}$ mampu melindungi ibu hanmil dari definisi Tablet Fe. Latar belakang pendidikan seseorang berhubungan dengan tingkat pengetahuan, dalam hal ini diharapkan pengetahuan gizi ibu baik, sehingga status gizi ibu hamil juga baik (citrakesuma, 2012)

Anemia selama kehamilan merupakan masalah kesehatan masyrakat yang utama dinegara berkembang. Prevalensi definisi anemia didunia berkisar 
antara (12-34\%). Di Sub Sahara Afrika anemia pada ibu hamil disebabkan oleh defisiensi nutrisi. Khususnya defisiensi Tablet Fe (Depkes, 2013).

Prevalensi anemia ibu hamil diindonesia adalah (40.1\%) yang dipengaruhi oleh berbagai faktor seperti sosial budaya dan penyebab secara langsung adalah ketidak seimbangan antara asupan makanan dan kebutuhan nutrisi. Upaya penanggulangan anemia gizi pada ibu hamil telah dilakukan sejak tahun 1975 melalui program seperti suplemen tablet $\mathrm{Fe}$, pengelolaan anemia kehamilan sesuai standar Antenatal Care, penyuluhan lewat media masa dan elektronik. Anemia merukan faktor penyebab tidak langsung kematian ibu dindonesia (Depkes, 2013)

Kepatuhan dalam mengkonsumsi tablet $\mathrm{Fe}$ adalah ketaatan ibu hamil melaksanakan anjuran program kesehatan untuk mengkonsumsi tablet Fe zat besi. Kapatuhan mengkonsumsi tablet zat besi diukur dengan ketepatan jumlah tablet yang dikonsumsi, ketepatan cara konsumsi tablet Fe dan frekuensi konsumsi perhari (Hidayah dan Anasari, 2012)

Dalam mengatasi masalah anemia pada ibu hamil dinas kesehatan provinsi Sumatera Selatan program sayang ibu mempunyai program suplementasi tablet tambah darah $(\mathrm{Fe})$ yang bisa didapatkan di puskesmas daerah. Tablet tambah Darah (Fe) dapat menghindari anemia besi dan anemia asam folat. Pada ibu hamil dianjurkan untuk mengkonsumsi tablet $\mathrm{Fe}$ minimal 90 tablet selama hamil. Pada beberapa ibu hamil, tablet $\mathrm{Fe}$ yang terkandung dalam vitamin kehamilan bisa menyebabkan sembelit atau diare (Khumaira, 2012)

Kabupaten OKU dengan jumlah ibu hamil 8.936 pada tahun 2013, sebanyak 1.085 (12,14\%) ibu hamil mengalami anemia. Tahun 2014 sebanyak 1.614 $(18,07 \%)$ dari 8933 ibu hamil (Dinkes kab. OKU, 2014)

Di UPTD Puskesmas Kemalaraja ibu hamil yang mengalami anemia tahun 2013 sebesar $212(25,35 \%)$ dari 836 ibu hamil, tahun 2014 ibu yang menderita anemia sebesar 251 (29,01\%) dari 865 ibu hamil dan tahun 2015 dari bulan januari maret berjumlah $27(8,25 \%)$ orang dari 327 ibu hamil.

Program pencegahan anemia ibu hamil di UPTD Puskesmas Kemalaraja telah dilakukan upaya antara lain deteksi dini pencegahan dan penanganan anemia melalui pelayanan antenatal care. Pemberian tablet $\mathrm{Fe} 90$ tablet selama kehamilan, pendidikan kesehatan tentang makanan yang bergizi dan pencegahan anemia, pemberian tablet anti malaria. Cakupan Fe ibu hamil pada tahun 2014 adalah sebesar (90\%), tetapi masih banyak ibu yang mengalami anemia (Data PWSKIA Dinkes OKU, 2015).

Mengingat komplikasi/akibat yang bisa timbul oleh adanya anemia selama kehamilan serta masih tingginya angka prevalensi kejadian anemia pada wanita 
Indonesia maka penulis tertarik untuk melakukan penelitian "hubungan kepatuhan mengkonsumsi tablet $\mathrm{Fe}$ terhadap kejadian anemia diwilayah kerja UPTD Puskesmas Kemalaraja kabupaten OKU tahun 2015)

\section{METODE PENELITIAN}

Penelitian ini menggunakan metode survey analitik yaitu "penelitian yang mencoba menggali bagaimana dan mengapa fenomena kesehatan itu terjadi" dan dengan pendekatan cross sectional dimana variabel independen dan variabel dependen dikumpulkan bersama-sama (Notoatmodjo, 2010).

Populasi pada penelitian ini adalah ibu yang memiliki balita di UPTD Puskesmas Kemalaraja Kabupaten Ogan Komering Ulu pada bulan Juli Tahun 2019 yang berjumlah 65 orang.

Sampel adalah bagian dari populasi yang di ambil pada saat penelitian, Sampel pada penelitian ini adalah seluruh adalah ibu yang memiliki balita di UPTD Puskesmas Kemalaraja Kabupaten Ogan Komering Ulu pada bulan Juli Tahun 2019 yang berjumlah 65 orang.

Penelitian ini dilakukan di UPTD Puskesmas Kemalaraja Kabupaten Ogan Komering Ulu tahun 2019. Waktu penelitian dilaksanakan pada bulan Mei-Agustus 2019.

\section{HASIL PENELITIAN}

Analisa ini dilakukan untuk mengetahui hubungan pemberian ASI Eksklusif, status imunisasi, dan berat badan lahir dengan kejadian Pneumonia menggunakan uji statistik Chi-Square memakai sistem komputerisasi SPSS (Statistic Programme For Social Science) dengan $p$ Value $=0,05$. Kedua variabel dikatakan ada hubungan jika $\mathrm{p}$ value $\leq$ 0,05 dan tidak ada hubungan jika $p$ value $>$ 0,05 . Dapat dilihat pada tabel sebagai berikut :

\section{Hubungan Pemberian ASI Ekslusif dengan Kejadian Pneumonia}

Untuk mengetahui hubungan antara variabel Independen (pemberian ASI Ekslusif) dan variabel dependen (kejadian Pneumonia) dilakukan uji Chi-Square. 
Hubungan Pemberian ASI Ekslusif dengan Kejadian Pneumonia di UPTD Puskesmas Kemalaraja Kabupaten Ogan Komering Ulu Tahun 2019.

\begin{tabular}{|c|c|c|c|c|c|c|c|c|}
\hline \multirow{3}{*}{$\begin{array}{l}\mathrm{N} \\
\mathrm{o}\end{array}$} & \multirow{3}{*}{$\begin{array}{c}\text { Pemb } \\
\text { erian } \\
\text { ASI } \\
\text { Ekslu } \\
\text { sif }\end{array}$} & \multicolumn{4}{|c|}{$\begin{array}{l}\text { Kejadian } \\
\text { Pneumonia }\end{array}$} & \multirow{2}{*}{\multicolumn{2}{|c|}{ Jumlah }} & \multirow{2}{*}{$\begin{array}{c}p \\
\text { valu } \\
e\end{array}$} \\
\hline & & \multicolumn{2}{|c|}{ Ya } & \multicolumn{2}{|c|}{ Tidak } & & & \\
\hline & & $\mathbf{F}$ & $\%$ & $f$ & $\%$ & $f$ & $\%$ & \\
\hline 1 & Tidak & 18 & $\begin{array}{c}81, \\
8\end{array}$ & 4 & $\begin{array}{c}18, \\
2\end{array}$ & 22 & 100 & רל \\
\hline 2 & $\mathrm{Ya}$ & 21 & $\begin{array}{c}48, \\
8\end{array}$ & 22 & $\begin{array}{c}51, \\
2\end{array}$ & 43 & 100 & 1 \\
\hline & $\underset{h}{\text { Jumla }}$ & 39 & $\begin{array}{c}60, \\
0\end{array}$ & 26 & $\begin{array}{c}40, \\
0\end{array}$ & 65 & 100 & \\
\hline
\end{tabular}

Berdasarkan Tabel 5.6 diketahui bahwa dari 39 responden yang pneuonia yang yang tidak mendapatkan ASI Eksklusif mengalami pneumonia berjumlah 18 responden $(81,8 \%)$ dan yang mendapatkan ASI Eksklusif berjumlah 21 responden $(48,8 \%)$.

Dari hasil uji Chi-Square diperoleh $p$ value $=0,021$ hal ini menunjukkan ada hubungan yang bermakna antara pemberian ASI Eksklusif dengan kejadian pneumonia.

Dengan demikian hipotesis yang menyatakan ada hubungan antara pemberian ASI Eksklusif dengan kejadian pneumona terbukti secara statistik.

\section{Hubungan Status Imunisasi dengan Kejadian ISPA}

Untuk mengetahui hubungan antara variabel Independen (status imunisasi) dan variabel dependen (kejadian Pneumonia) dilakukan uji Chi-Square dimana hasilnya dapat dilihat pada tabel 5.5

Hubungan status imunisasi dengan Kejadian Penumonia di UPTD Puskesmas Kemalaraja Kabupaten Ogan Komering Ulu Tahun 2019.

\begin{tabular}{|c|c|c|c|c|c|c|c|c|}
\hline \multirow{3}{*}{$\begin{array}{l}\mathrm{N} \\
\mathrm{O}\end{array}$} & \multirow{3}{*}{$\begin{array}{l}\text { Status } \\
\text { Imunis } \\
\text { asi }\end{array}$} & \multicolumn{4}{|c|}{$\begin{array}{c}\text { Kejadian } \\
\text { Pneumonia }\end{array}$} & \multirow{2}{*}{\multicolumn{2}{|c|}{ Jumlah }} & \multirow{2}{*}{$\begin{array}{c}p \\
\text { valu } \\
e\end{array}$} \\
\hline & & \multicolumn{2}{|c|}{$\mathrm{Ya}$} & \multicolumn{2}{|c|}{ Tidak } & & & \\
\hline & & $\mathbf{F}$ & $\%$ & $f$ & $\%$ & $f$ & $\%$ & \\
\hline 1 & $\begin{array}{l}\text { Tidak } \\
\text { Lengka } \\
\mathrm{p}\end{array}$ & 24 & $\begin{array}{c}80, \\
0\end{array}$ & 6 & $\begin{array}{c}20, \\
0\end{array}$ & 30 & 100 & 0,00 \\
\hline 2 & $\begin{array}{l}\text { Lengka } \\
\mathrm{p}\end{array}$ & 15 & $\begin{array}{c}42, \\
9\end{array}$ & 20 & $\begin{array}{c}57, \\
1\end{array}$ & 35 & 100 & 5 \\
\hline & Jumlah & 39 & $\begin{array}{c}60, \\
0\end{array}$ & 26 & $\begin{array}{c}40, \\
0\end{array}$ & 65 & 100 & \\
\hline
\end{tabular}

Berdasarkan Tabel 5.5 diketahui bahwa dari 30 responden yang status imunisasi tidak lengkap mengalami pneumonia berjumlah 24 responden $(80,0 \%)$ dan dari 35 responden yang status imunisasi lengkap mengalami pneumonia berjumlah 15 responden (42,9\%).

Dari hasil uji Chi-Square diperoleh $p$ value $=0,005$ hal ini menunjukkan ada hubungan yang bermakna antara status imunisasi dengan kejadian pneumonia. 
Dengan demikian hipotesis yang menyatakan ada hubungan antara status imunisasi dengan kejadian pneumonia terbukti secara statistik.

\section{Hubungan berat badan lahir dengan Kejadian pneumonia}

Untuk mengetahui hubungan antara variabel Independen (berat badan lahir) dan variabel dependen (kejadian Pneumonia) dilakukan uji Chi-Square.

Hubungan berat badan lahir dengan Kejadian pneumonia di UPTD Puskesmas Kemalaraja Kabupaten Ogan Komering Ulu Tahun 2019

\begin{tabular}{|c|c|c|c|c|c|c|c|c|}
\hline \multirow{3}{*}{$\begin{array}{l}\mathbf{N} \\
\mathbf{0}\end{array}$} & \multirow{3}{*}{$\begin{array}{c}\text { Berat } \\
\text { Bada } \\
n \\
\text { Lahir }\end{array}$} & \multicolumn{4}{|c|}{$\begin{array}{c}\text { Kejadian } \\
\text { Pneumonia }\end{array}$} & \multirow{2}{*}{\multicolumn{2}{|c|}{ Jumlah }} & \multirow{3}{*}{$\begin{array}{c}p \\
\text { valu } \\
e\end{array}$} \\
\hline & & \multicolumn{2}{|c|}{ Ya } & \multicolumn{2}{|c|}{ Tidak } & & & \\
\hline & & $\mathbf{F}$ & $\%$ & $f$ & $\%$ & $f$ & $\%$ & \\
\hline 1 & BBLR & $\begin{array}{l}1 \\
8\end{array}$ & $\begin{array}{c}78, \\
3\end{array}$ & 5 & $\begin{array}{c}21, \\
7\end{array}$ & $\begin{array}{l}2 \\
3\end{array}$ & $\begin{array}{c}10 \\
0\end{array}$ & \\
\hline 2 & $\begin{array}{l}\text { Tidak } \\
\text { BBLR }\end{array}$ & $\begin{array}{l}2 \\
1\end{array}$ & $\begin{array}{c}50 \\
0\end{array}$ & $\begin{array}{l}2 \\
1\end{array}$ & $\begin{array}{c}50, \\
0\end{array}$ & $\begin{array}{l}4 \\
2\end{array}$ & $\begin{array}{c}10 \\
0\end{array}$ & 0 \\
\hline & $\begin{array}{c}\text { Jumla } \\
\mathbf{h}\end{array}$ & $\begin{array}{l}3 \\
9\end{array}$ & $\begin{array}{c}60 \\
0\end{array}$ & $\begin{array}{l}2 \\
6\end{array}$ & $\begin{array}{c}40, \\
0\end{array}$ & $\begin{array}{l}6 \\
5\end{array}$ & $\begin{array}{c}10 \\
0\end{array}$ & \\
\hline
\end{tabular}

Berdasarkan Tabel 5.6 diketahui bahwa dari 23 responden dengan berat badan BBLR mengalami pneumonia berjumlah 18 responden $(78,3 \%)$ dan dari 42 responden dengan berat badan tidak BBLR mengalami pneumonia berjumlah 21 responden $(50,0 \%)$.
Dari hasil uji Chi-Square diperoleh $p$ value $=0,050$ hal ini menunjukkan ada hubungan yang bermakna antara berat badan dengan kejadian penumonia.

Dengan demikian hipotesis yang menyatakan ada hubungan antara berat badan dengan kejadian pneumonia terbukti secara statistik.

\section{PEMBAHASAN}

Dalam penelitian ini variabel pemberian ASI eksklusif dibagi menjadi 2 kategori yaitu ya (bila anak mendapatkan ASI secara Eksklusif selama 6 bulan) dan tidak (bila anak tidak mendapatkan ASI secara Eksklusif selama 6 bulan).

Berdasarkan analisa bivariat diketahui bahwa dari 43 responden yang mendapatkan ASI Eksklusif yang mengalami pneumonia berjumlah 21 responden $(48,8 \%)$ dan dari 22 responden yang tidak mendapatkan ASI Eksklusif mengalami pneumonia berjumlah 18 responden $(81,8 \%)$.

Dari hasil uji Chi-Square diperoleh $p$ value $=0,021$ hal ini menunjukkan ada hubungan yang bermakna antara pemberian ASI Eksklusif dengan kejadian pneumonia. Dengan demikian hipotesis yang menyatakan ada hubungan antara pemberian ASI Eksklusif dengan kejadian pneumona terbukti secara statistik. 
Dalam penelitian ini variabel status imunisasi dibagi menjadi 2 kategori yaitu lengkap (jika balita mendapat kelengkapan imunisasi dasar) dan tidak lengkap (jika balita tidak mendapat kelengkapan imunisasi dasar). Berdasarkan analisa bivariat diketahui bahwa dari 30 responden yang status imunisasi tidak lengkap mengalami pneumonia berjumlah 24 responden $(80,0 \%)$ dan dari 35 responden yang status imunisasi lengkap mengalami pneumonia berjumlah 15 responden $(42,9 \%)$.

Dari hasil uji Chi-Square diperoleh $p$ value $=0,005$ hal ini menunjukkan ada hubungan yang bermakna antara status imunisasi dengan kejadian pneumonia. Dengan demikian hipotesis yang menyatakan ada hubungan antara status imunisasi dengan kejadian pneumonia terbukti secara statistik.

Dalam penelitian ini variabel berat badan lahir dibagi menjadi 2 kategori yaitu BBLR (bila berat badan lahir kurang dari 2500 gram) dan tidak BBLR (bila berat badan lahir 2500-4000 gram). Berdasarkan analisa bivariat diketahui bahwa dari 23 responden dengan berat badan beresiko mengalami pneumonia berjumlah 18 responden $(78,3 \%)$ dan dari 42 responden dengan berat badan tidak beresiko mengalami pneumonia berjumlah 21 responden $(50,0 \%)$.

Dari hasil uji Chi-Square diperoleh $p$ value $=0,050$ hal ini menunjukkan ada hubungan yang bermakna antara berat badan dengan kejadian penumonia. Dengan demikian hipotesis yang menyatakan ada hubungan antara berat badan dengan kejadian pneumonia terbukti secara statistik.

Hasil penelitian ini sejalan dengan hasil penelitian Aldriana (2015) menunjukkan hubungan yang bermakna antara Berat Badan Lahir dengan kejadian Pneumonia pada Balita di wilayah kerja Puskesmas Rambah Samo 1 tahun 2014.

\section{KESIMPULAN}

Dari hasil penelitian yang telah dilakukan di UPTD Puskesmas Kemalaraja Kabupaten Ogan Komering Ulu Tahun 2019, dapat disimpulkan bahwa :

1. Ada hubungan yang bermakna antara Status Imunisasi dengan Kejadian Pneumonia di UPTD Puskesmas Kemalaraja Tahun 2017 dengan uji statistik didapat $p$ value $0,005<0,05$.

2. Ada hubungan yang bermakna antara Pemberian ASI Eksklusif dengan Kejadian Pneumonia di UPTD Puskesmas Kemalaraja Tahun 2019 dengan uji statistik didapat $p$ value $0,021<0,05$

3. Ada hubungan yang bermakna antara berat badan lahir dengan Kejadian Pneumonia di UPTD Puskesmas Kemalaraja Tahun 2019 dengan uji statistik didapat $p$ value $0,050<0,050$. 


\section{DAFTAR PUSTAKA}

AMD (Albaity Mohamed). Pneumonia the forgotten killer of children. Jakarta.2008

Anin , 2012. Pneumonia pada anak. Jakarta : EGC

Depkes RI, 2012, Rencana Pemberian Imunisasi Dasar Anak, www.depkes.go.id

Depkes RI Pusat Buletin Jendela Epidemiologi. Pneumonia balita. 2013.http://www.depkes.go.id/downl oad.php?file=download/pusdatin/bul etin/buletin-pneumonia.pdf

Harahap, S. 2011. Analisis Faktor Risiko Yang Berhubungan Dengan Kejadian Pneumonia Pada Anak Balita Di RSUD Pasar Rebo Jakarta. Jakarta : Universitas Indonesia

Hidayat, Alimul Azis. 2010. Metode Penelitian Kebidanan Teknik Analisa Data. Jakarta: Salemba Medika.

Kementerian Kesehatan RI. 2013.Buletin Jendela Epidemiologi Volume 3. Jakarta : Kemenkes RI.

Machmud R , 2012 . Pneumonia Balita di Indonesia dan Peran Kabupaten dalam Menanggulanginya.

Padang:Andalas University.

Marhamah,A.Arsunan Arsin,Wahidduddin 2012. Faktoryang berhubungan dengan kejadian ISPA pada nak balita di Desan Bontongan Kabupaten Enrekang. Makasar: UHM

Maryunani Anik, 2013. Ilmu Kesehatan Anak dalam Kebidanan. Jakrta; Trans Info Media

Muchlastriningsih (2008). Analisis faktor risiko kejadian pneumonia pada balita di wilayah kerja Puskesmas Sidorejo Kota Pagar Alam. Jurnal Kesehatan Lingkungan Indonesia. 2008:82-5.
Nana Aldriana, 2015. Faktor yang Berhubungan Dengan Pneumonia pada Balita di Wilayah Kerja Puskesmas Rambah Samo I Tahun 2014. Universitas Pasir Pengaraian

Notoatmodjo, S. 2012. Metodologi Penelitian Kesehatan Edisi Revisi. Jakarta: PT Rineka Cipta

Ngastiyah Ani, 2012. Perawatan Anak Sakit Edisi 2. Jakarta: EGC

Rahmin, Rizka, 2011. Faktor yang Berhubungan Dengan Kejadian Suspek Pneumonia pada Balita di Wilayah Kota Payakumbuh. Universitas Andalas

Roesli U. 2011. Mengenal ASI Eksklusif. Jakarta : Trubus Agriwidya

Said M. Pneumonia. Dalam: Buku Ajar Respirologi Anak. Ikatan Dokter Anak Indonesia (IDAI): Jakarta; 2010. hlm.350-65.

Sukmawati dan Sri Dara. 2011. Hubungan Status Gizi, Berat Badan Lahir (BBL),Imunisasi dengan Kejadian Infeksi Saluran Pernapasan Akut (ISPA) pada Balita di Wilayah Kerja Puskesmas Tunikamaseang Kabupaten Maros Media Gizi Pangan, Vol. X, Edisi 2, Juli Desember 2011 (Online)

Tedjo Nelson. (2012). Ilmu Kesehatan Anak vol. 1. Jakarta : EGC

Unaids, 2012, Perawatan lbu Hamil dan Bayi, Jakarta, Pustaka Sinar Harapani

Widarini, Sumasari. 2013. Hubungan antara Pemberian ASI Eksklusif dengan Kejadian ISPA pada Balita di Wilayah Kerja Puskesmas Sempor II Kabupaten Kebumen Tahun 2012. Jurnal IImiah Kesehatan Keperawatan, Volume 6, No. 1, Februari 2013 